\title{
The intestine and human immunodeficiency virus
}

The intestinal tract is a major target organ for human immunodeficiency virus (HIV). Gastrointestinal syndromes resulting from HIV infection are common $^{1}$ and whilst not often acutely life threatening are a major cause of morbidity and contribute to the cachexia seen in end-stage HIV infection. ${ }^{2}$ In addition, the intestinal tract is a mucosal surface through which HIV infection may be acquired either in the rectum or in the upper intestinal tract of the neonate after breast feeding. ${ }^{3}$

Diarrhoea is a common chronic clinical problem in HIV infection. In contrast, acute transient profuse watery diarrhoea is well recognised during the acute illness characterising seroconversion to HIV. ${ }^{4}$ The mechanism of the acute diarrhoea is not understood but may represent trafficking of activated HIVinfected macrophages and lymphocytes (vide infra) to the intestinal mucosa during the viraemic phase which characterises HIV seroconversion. In the later phases of HIV infection, diarrhoea may result from opportunist enteric infection in the small or large intestine. ${ }^{5}$ Such infections, unlike transient enteritic syndromes in immunocompetent subjects, usually persist for the remainder of the life of the patient. Any enteropathogen can become an opportunist in stage IV HIV infection. The precise mechanisms of mucosal immunodeficiency in AIDS are not yet understood, but impaired antigen presentation and consequently depressed mucosal immune responses must be central to the problem. There are few studies dealing with failure of mucosal immune mechanisms during HIV infection in vivo. However, reduced serum antibody response to wild-type Giardia lamblia infection in male homosexuals infected with HIV has been described. ${ }^{6}$ Little is known about reduced cellular immunity to enteropathogens during the course of HIV infection. However, it is generally accepted that opportunist infection does not usually occur in HIV infection until the peripheral blood CD4 lymphocyte counts fall below $c .0 \cdot 2 \times 10^{9}$ cells $/ \mathrm{L}$.

Cryptosporidial infection affects both the small and large intestinal mucosa causing severe chronic watery diarrhoea by an unknown pathophysiological mechanism. ${ }^{7}$ Cryptosporidial enteritis is not amenable to chemotherapy and is a source of much human misery. In contrast, diarrhoeal disease with Isospora belli is at least partially treatable with co-trimoxazole. ${ }^{8}$ Salmonella infection has proved a particular clinical problem during HIV disease since, as in other T cell deficiency states, the organism is carried persistently in the faeces of infected individuals and may, at unpredictable intervals, cause severe bacteraemic illness requiring antibiotic treatment. ${ }^{9}$ Acute salmonella bacteraemia is particularly important in slim disease, ${ }^{10}$ a major lifethreatening event accompanying HIV infection in Africa. ${ }^{11}$

Enteroviral infections are common during the course of HIV infection $;{ }^{12}$ most of these infections are untreatable. In cytomegalovirus infection, which may affect both small and large intestine, ganciclovir has been used to good symptomatic effect but the life span of patients does not appear to be improved. ${ }^{13}$

Diarrhoeal disease is well described in patients with HIV infection in the absence of demonstrable enteropathogens in stool or intestinal tissue; disease of the small intestine is characterised by partial villous atrophy and crypt hyperplasia. Such histological changes have been described in asymptomatic (stage II) HIV infection in male homosexuals. ${ }^{14}$ These histological changes have been termed HIV enteropathy and have been shown to result in fat malabsorption. ${ }^{14}$ The debate concerning pathophysiological mechanisms of HIV enteropathy is still unresolved. The tempting hypothesis is that HIV per se is directly enteropathogenic and HIV has been detected by in-situ hybridisation in biopsies of the duodenum and large intestine from patients with AIDS. However, considerable controversy still exists as to the character of the cells infected by HIV in such mucosal biopsies; HIV infection of epithelial cells, thought to be of argentochromaffin lineage, has been described. ${ }^{15}$ Other groups have not been able to confirm this and suggest that the reticulo-endothelial cells of the lamina propria, particularly macrophages, contain the HIV genome ${ }^{16}$ It has been suggested also that lymphatic obstruction may be a major cause of dysfunction of the small intestine in HIV infection, ${ }^{17}$ autonomic denervation is common in the small intestine of HIV-infected individuals ${ }^{18}$ and this may result in malabsorption and intestinal dysmotility.

Direct in-vitro HIV infection of human fetal intestinal explants involving only macrophages and lymphocytes has recently been described. ${ }^{19}$ In these experiments mucosal reticulo-endothelial cells of the colon and small intestine were shown to be productively infected with HIV with no evidence of any epithelial cell infection. In addition, detailed morphometric analysis of mucosal explants infected with HIV in vitro revealed increased mitotic activity in crypt cells ( $P$. Batman, G. E. Griffin, unpublished observations) which may resemble the crypt hyperplasia seen in vitro in biopsies of the small intestine. The potential link 
between such in-vitro observations and the resulting histopathological change seen in the intestine is that HIV-infected macrophages become activated and as a result secrete cytokines which have been shown previously to cause alteration of villus architecture. ${ }^{20}$

The potential for breast feeding to spread HIV infection has now been established. ${ }^{4}$ Such a route of infection has a devastating effect in developing countries, such as Africa. where breast feeding is essential for infant survival and cannot be proscribed. In contrast. in developed countries breast feeding should be very strongly discouraged among the progressively increasing numbers of HIV-infected women bearing children.

The study of intestinal pathology in HIV infection is a challenging frontier which is enabling better clinical management of HIV-infected patients and a clearer understanding of immunological and viral mechanisms undermining intestinal function. However, much additional information is still needed, before effective rational therapy can be achieved; e.g., in the chemotherapy of coccidial infection and in the understanding of the mucosal immune deficit in HIV infection. In addition, since the intestine is a major route of HIV infection, there is currently great interest. particularly in animal models, in contriving protective mucosal immunity to HIV by the mucosal route of vaccination.

G. E. GRIFFIN

Division of Communicable Diseases. St George's Hospitil Medical School, Tooting. London SW 17 ORE.

\section{References}

1. Griflin GE. Gastrointestinal manifestations of HIV infection In: Harris TRW. Forster $S$ (eds) Recent advances in STD and AlDS 4. Edinburgh. Churchill Livingstone. 1991: 17.33

2. Grunfeld C. Feingold KR. Metabolic disturbances and wasting in the acquired immunodeficiency syndrome. $N$ Engl $J$ Med 1992:327:329:337

3. Van de Perre P. Simonon A. Msellati P ot al Postnatal transmission of Human Immunodeficiency Virus type 1 from mother to infant. A prospective cohort study in Kigoli, Rwanda. N Engl J Med 1991 : 325: 593-598.

4. Clark SJ. Saag MS. Decker WD et al. High titres of cytopathic virus in plasma of patients with symptomatic HIV-1 inlection. N Eny/J Med 1991: $324: 954960$.
5. Smith PD, Lane C. Gill VJ et al. Intestinal infections in patients with acquired immunodeficiency syndrome (AIDS). Etiology and response to therapy. Ann Intern Med 1988; 108 : $328-333$.

6. Janoff EN, Smith PD, Blaser MJ. Acute antibody responses to Giardia lamblia are depressed in patients with AIDS. $J$ Infect Dis 1988; 157: 798 804.

7. Connolly GM, Dryden MS, Shanson DC, Gazzard BG. Cryptosporidial diarrhoea in AIDS and its treatment. Gut $1988: 29: 593-597$.

8. DeHovitz JA, Pape JW, Boncy M, Johnson WD. Clinical manifestations and therapy of Isopora belli infection in patients with the acquired immunodeficiency syndrome. $N$ Enyl J Med 1986; 315: 87-90.

9. Levine WC. Buehler JW, Bean NH, Tauxe RV. Epidemiology of nontyphoidal Salmonella bacteraemia during the human immunodeficiency virus epidemic. I Infect Dis 1991; 164: $81-87$.

10. Serwadda D, Mugerwa RD, Sewankambo NK et al. Slim disease: a new disease in Uganda and its association with HTLV-III infection. Lancet $1985 ; 2: 849-852$.

11. Gilks CF, Brindle RJ, Otieno LS et al. Life-threatening bacteraemia in HIV-1 seropositive adults admitted to hospital in Nairobi, Kenya. Lancet 1990; 1 : 545-549.

12. Cunningham AL, Grohman GS, Harkness J et al. Gastrointestinal viral infections in homosexual men who were symptomatic and seropositive for human immunodeficiency virus. J Infect Dis 1988; $158: 386391$.

13. Chachoua A. Dieterich D, Krasinski K et al. 9-(1,3-dihydroxy2-propoxymethyl) guanine (gangiclovir) in the treatment of cytomegalovirus gastrointestinal disease in the acquired immunodeficiency syndrome. Ann Intern Med 1987; 107: $133-137$.

14. Miller ARO, Griffin GE, Batman et al. Jejunal mucosal architecture and fat absorption in male homosexuals infected with human immunodeficiency virus. $Q J \mathrm{Med}$ 1988: 69: 1009-1019.

15. Nelson JA. Wiley CA, Reynolds-Kohler C, Reese CE, Margaretten W. Levy JA. Human immunodeficiency virus detected in bowel epithelium from patients with gastrointestinal symptoms, Lancet 1988: 1: 259-262.

16. Fox CH, Kotler D, Tierney A, Wilson CS, Fauci AS. Detection of HIV-1 RNA in the lamina propria of patients with AIDS and gastrointestinal disease. $J$ Infect Dis 1989; 159: $467-471$.

17. Ehrenpreis ED, Patterson BK, Brainer et al. Histopathologic findings of duodenal biopsy specimens in HIV-infected patients with and without diarrhea and malabsorption. $A m$ J Clin Pathol 1992: 97: 21-28.

18. Batman P. Miller ARO, Sedgwick PM. Griffin GE. Autonomic denervation in jejunal mucosa of homosexual men infected with HIV. AIDS $1991 ; 5: 12471252$.

19. Fleming SC. Kapembwa MS, MacDonald TT, Griffin GE. Direct in vitro infection of human small intestine and colon with Human Immunodeficiency Virus (HIV-1). AIDS 1992; 6: $1099-1104$.

20. MacDonald TT, Spencer J. Evidence that activated mucosal T Cells play a role in the pathogenesis of enteropathy in human small intestine. $J$ Exp Med 1988; 167: 1341-1349. 